Research Article

Human and Medical Genetics

\title{
Large miRNA survival analysis reveals a prognostic four-biomarker signature for triple negative breast cancer
}

\author{
Fernando Andrade ${ }^{1 *}$, Asuka Nakata ${ }^{2,3^{*}}$, Noriko Gotoh $^{2}$ and André Fujita ${ }^{4}$ iD \\ ${ }^{1}$ Universidade de São Paulo, Programa Internunidades de Pós-Graduação em Bioinformática, São Paulo, \\ SP, Brazil. \\ ${ }^{2}$ Kanazawa University, Cancer Research Institute, Division of Cancer Cell Biology, Kanazawa, Ishikawa, \\ Japan. \\ ${ }^{3}$ Universidade de São Paulo, Faculdade de Medicina, Departamento de Pediatria, São Paulo, SP, Brazil. \\ ${ }^{4}$ Universidade de São Paulo, Instituto de Matemática e Estatística, Departamento de Ciência de \\ Computação, São Paulo, SP, Brazil.
}

\begin{abstract}
Triple negative breast cancer (TNBC) is currently the only major breast tumor subtype without effective targeted therapy and, as a consequence, usually presents a poor outcome. Due to its more aggressive phenotype, there is an urgent clinical need to identify novel biomarkers that discriminate individuals with poor prognosis. We hypothesize that miRNAs can be used to this end because they are involved in the initiation and progression of tumors by altering the expression of their target genes. To identify a prognostic biomarker in TNBC, we analyzed the miRNA expression of a cohort composed of 185 patients diagnosed with TNBC using penalized Cox regression models. We identified a four-biomarker signature based on miR-221, miR-1305, miR-4708, and RMDN2 expression levels that allowed for the subdivision of TNBC into high- or low-risk groups (Hazard Ratio $-\mathrm{HR}=0.32 ; 95 \%$ Confidence Interval $-\mathrm{Cl}=$ $0.11-0.91 ; p=0.03$ ) and are also statistically associated with survival outcome in subgroups of postmenopausal status ( $\mathrm{HR}=0.19 ; 95 \% \mathrm{Cl}=0.04-0.90 ; p=0.016)$, node negative status $(\mathrm{HR}=0.12 ; 95 \% \mathrm{Cl}=0.01-1.04 ; p=0.026)$, and tumors larger than $2 \mathrm{~cm}(\mathrm{HR}=0.21 ; 95 \% \mathrm{Cl}=0.05-0.81 ; p=0.021)$. This four-biomarker signature was significantly associated with TNBC as an independent prognostic factor for survival.
\end{abstract}

Keywords: miRNA, miR-221, miR-1305, miR-4708, RMDN2.

Received: September 25, 2018; Accepted: April 11, 2019.

\section{Introduction}

Breast cancer is the most common cancer among women, with an estimated 246,660 new cases and 40,450 deaths in 2016 in the United States (Siegel et al., 2016). Based on gene expression profiling, most studies categorize breast cancer into the following four major molecular subtypes: luminal A (presence of estrogen receptor $-\mathrm{ER}^{+}$and/or progesterone receptor $-\mathrm{PR}^{+}$, and absence of HER2 expression - HER2 $\left.{ }^{-}\right)$, luminal B $\left(\mathrm{ER}^{+}\right.$and/or $\left.\mathrm{PR}^{+}, \mathrm{HER}^{+}\right)$, HER2 type $\left(\mathrm{ER}^{-}, \mathrm{PR}^{-}, \mathrm{HER} 2^{+}\right)$, and triple negative $\left(\mathrm{ER}^{-}, \mathrm{PR}^{-}\right.$, and HER2) (Risbridger et al., 2010).

Developments in the treatment of some types of breast cancer have increased the overall survival of patients (Vogel et al., 2002; Ariazi et al., 2006; Dawood et al., 2009). For example, tamoxifen, which is an antagonist of the estrogen re-

Send correspondence to André Fujita. Universidade de São Paulo, Instituto de Matemática e Estatística, Departamento de Ciência de Computação, Rua do Matão, 1010, Cidade Universitária, 05508-090, São Paulo, SP, Brazil. E-mail: andrefujita@usp.br. 'These authors contributed equally to this work. ceptor, and trastuzumab, which is a monoclonal antibody that acts on the HER2 receptor, have improved the survival outcome of luminal and HER2 breast cancer subtypes, respectively. However, predictive molecular biomarkers and targeted therapies are still lacking for the treatment of triple negative breast cancer (TNBC) (Gonzalez-Angulo et al., 2007; Blows et al., 2010; Iwase et al., 2010; The Cancer Genome Atlas Network, 2012). This may be the reason for the low improvement of survival rates of TNBC patients in the last years (Gonzalez-Angulo et al., 2007). TNBC is a very heterogeneous disease, which comprises between $12 \%$ and $24 \%$ of all breast cancers and is associated with early recurrence of disease, a more aggressive phenotype, and a worse clinical prognosis than luminal and HER2 types (Gasparini et al., 2014). Currently, the only option of treatment for patients diagnosed with TNBC is chemotherapy, which has limited benefits to a subgroup of patients. Thus, a molecular stratification of TNBC based on molecular markers is essential to identify novel targets of drugs.

We focused our research on microRNAs (miRNAs) because they are widely known to be critical components in 
cancer progression and drug resistance. miRNAs are small (19 - 25 nucleotides) single-stranded non-coding RNA molecules that regulate protein-coding genes through sequence-specific binding to 3' untranslated regions (UTRs) of messenger RNAs (mRNA) (Zeng et al., 2003; Bartel, 2004). As a consequence, they alter the abundance of gene expression, usually reducing gene expression, but a few reports have suggested that they may also induce gene expression (Vasudevan et al., 2007; Place et al., 2008).

Compelling evidence has shown that aberrantly expressed miRNAs are involved in the initiation and progression of human cancers and have considerable potential for use as biomarkers for the detection, diagnosis, classification, and treatment of cancer. Different tissue types present unique expression levels of each miRNA and thereby present unique miRNA "signatures." Similarly, each tumor type presents a unique miRNA signature, which can be used to identify the tissue of origin of metastatic tumors and to discriminate between distinct cancer subtypes (Lu et al., 2005). Thus, the sub-classification of TNBC using miRNAs may identify new screening methods, prognostic factors, and potential targets for personalized medicine (Cascione et al., 2013).

In an attempt to identify molecular prognostic markers specific to TNBC, we analyzed a large TNBC cohort composed of 185 patients and approximately 850 miRNAs (Dvinge et al., 2013). By computational analysis, we identified a four-biomarker signature that is statistically associated with patients' outcomes in both training and validation TNBC sets.

\section{Materials and Methods}

\section{MicroRNA expression data}

A collection of clinically annotated and previously pre-processed public miRNA/mRNA gene expression data (Agilent) composed of approximately 850 miRNAs (including putative miRNAs) and 185 subjects diagnosed with TNBC were downloaded from the European Genomephenome Archive webpage. This dataset (ID EGAS00000000122) was derived from fresh-frozen cancer specimens from tumor banks in the United Kingdom and Canada. The treatments were homogeneous for clinically relevant groupings. The selection criterion for the TNBC patients was based on the presence or absence of $E R, P R$, and $H E R 2$ empirical gene expression distributions. To define the presence or absence of specific gene expression, Curtis et al. (2012) clustered the individuals into two groups by using a clustering expectation-maximization algorithm (Gaussian mixture model). Individuals belonging to the cluster with lower gene expression were set as with absent gene expression and otherwise as present. They carried out this procedure for each one of the three genes (ER, $P R$, and HER2). We selected all individuals with simultaneously absent $E R, P R$, and HER 2 gene expression. Basic information regarding this 185 patients data set is as follows (mean \pm standard deviation or number of individuals): age at diagnosis (54.99 \pm 14.37 years old), tumor size $(2.72 \pm 18.25 \mathrm{~cm})$, presence $(87)$, absence (95), and unknown (3) of lymph nodes, grades 1 (1), 2 (20), 3 (159), and unknown (5), subjects in premenopausal (70), postmenopausal (114), and unknown (1), histological type (infiltrating ductal carcinoma (171), infiltrating lobular carcinoma (7), ductal carcinoma in situ (2), invasive tumor (3), and benign (2)).

The 185 patients were randomized and split into training $(n=120)$ and validation $(n=65)$ sets. The clinical and pathological characteristics of both training and validation sets are summarized in Table 1.

\section{Statistical analysis}

Because the number of miRNAs (approximately 850) is higher than the number of observations in the training set $(\mathrm{n}=120)$, standard Cox proportional hazard regression is not applicable. Thus, we first used the lasso regularized Cox regression for feature selection (Friedman et al., 2010) to select the miRNAs that are mostly associated with overall survival time. Then, to accurately estimate the weights of each feature selected by the penalized Cox regression model (coefficients estimated by lasso regularized Cox regression are known to be biased due to $l_{1}$ penalization), we applied the

Table 1 - Clinical and pathological characteristics of patients and their tumors in both the training and validation sets. The data are numbers (\%) unless otherwise stated. SD: standard deviation.

\begin{tabular}{|c|c|c|c|}
\hline Variables & Status & $\begin{array}{l}\text { Training set } \\
(\mathrm{n}=120)\end{array}$ & $\begin{array}{c}\text { Validation set } \\
\quad(\mathrm{n}=65)\end{array}$ \\
\hline \multirow{5}{*}{$\begin{array}{l}\text { Age at diagnosis } \\
\text { (years) }\end{array}$} & Mean (SD) & $55.93(14.47)$ & $53.25(14.13)$ \\
\hline & $\leq 40$ & $22(18.3)$ & $13(20.0)$ \\
\hline & $41-55$ & $33(27.5)$ & $21(32.3)$ \\
\hline & $56-70$ & $47(39.2)$ & $24(36.9)$ \\
\hline & $>70$ & $18(15.0)$ & $7(10.8)$ \\
\hline \multirow[t]{4}{*}{ Tumor size $(\mathrm{cm})$} & Mean (SD) & $2.76(1.96)$ & $2.64(1.49)$ \\
\hline & $\leq 2 \mathrm{~cm}$ & $50(41.7)$ & $27(41.5)$ \\
\hline & $>2 \mathrm{~cm}$ & $69(57.5)$ & $36(55.4)$ \\
\hline & Unknown & $1(0.8)$ & $2(3.1)$ \\
\hline \multirow[t]{3}{*}{ Lymph nodes } & Negative & $59(49.2)$ & $28(43.1)$ \\
\hline & Positive & $60(50.0)$ & $35(53.8)$ \\
\hline & Unknown & $1(0.8)$ & $2(3.1)$ \\
\hline \multirow[t]{4}{*}{ Grade } & 1 & $1(0.8)$ & $0(0)$ \\
\hline & 2 & $14(11.7)$ & $6(9.2)$ \\
\hline & 3 & $101(84.2)$ & $58(89.2)$ \\
\hline & Unknown & $4(3.3)$ & $1(1.6)$ \\
\hline \multirow{3}{*}{$\begin{array}{l}\text { Menopausal } \\
\text { status }\end{array}$} & Premenopausal & $45(37.5)$ & $25(38.5)$ \\
\hline & Postmenopausal & $75(62.5)$ & $39(60.0)$ \\
\hline & Unknown & $0(0)$ & $1(1.5)$ \\
\hline \multirow[t]{2}{*}{ Dead } & Yes & $54(46.7)$ & $27(41.5)$ \\
\hline & No & $64(53.3)$ & $39(58.5)$ \\
\hline
\end{tabular}


standard Cox regression. Figure 1 summarizes the analysis in a flowchart. To minimize the influence of clinical variables, such as age at diagnosis, tumor grade, size, presence/absence of nodes, and menopausal status, we included them as covariates in the standard Cox regression model.

The risk score for each patient was calculated by multiplying the expression level of each miRNA by its corresponding coefficient obtained by the Cox regression in the training set and summing them. Patients were thus dichotomized into the groups at good or poor prognosis (low or high risk) using the median cutoff of the risk score as the threshold value.

Kaplan-Meier survival curves and log-rank tests were constructed to evaluate the differences in the overall survival time of predicted good and poor prognosis groups by the miRNA signature in both the training and validation sets. Univariate and multivariate analyses with the Cox proportional hazard model were used to assess the prognostic value of the miRNA signature with and without adjusting for indi-

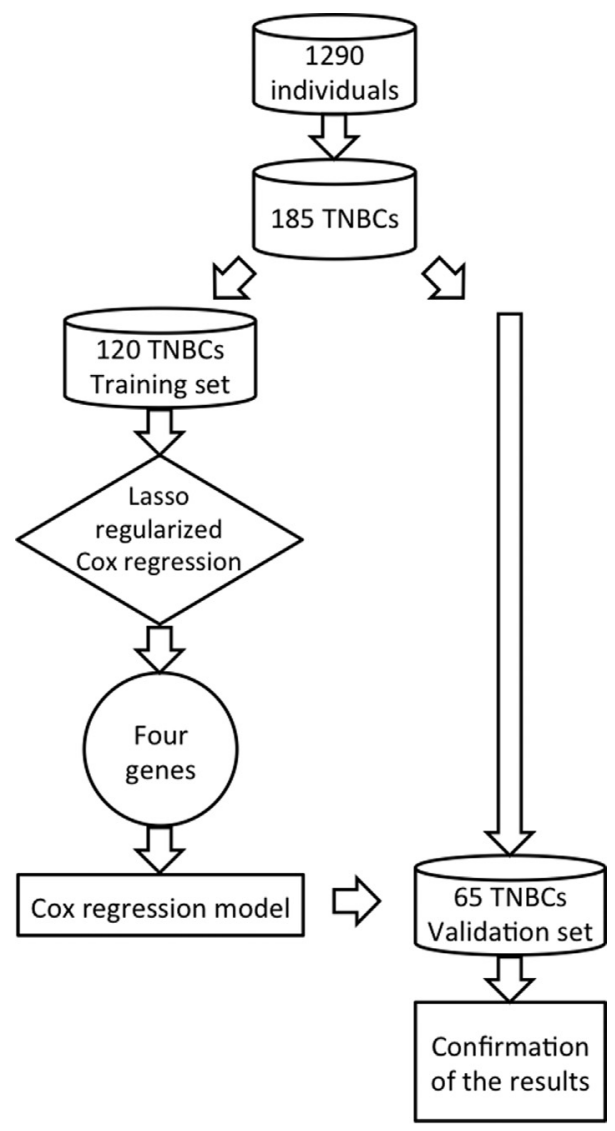

Figure 1 - Scheme for the data analysis. We selected 185 individuals with an absent expression of ER, PR, and HER2 from a breast cancer data set composed of 1,290 individuals. This subset of 185 TNBCs was split into training (120 individuals) and validation (65 individuals) sets. To select biomarkers associated with overall TNBC survival, we used the Lasso regularized Cox regression model on the training set. Four genes were selected by the method. Then, to better estimate the parameters of the model, we used the standard Cox regression model. Finally, we confirmed the results obtained in the training set by applying the four-biomarkers in the validation set. vidual clinical prognostic variables (age at diagnosis, tumor grade, tumor size, presence/absence of nodes, and menopausal status), respectively.

To investigate the differential expression of miRNAs between good and poor prognosis, we performed a Wilcoxon signed-rank test, which is more robust to outliers than the t-test.

To identify the correlation between miRNAs and their respective target gene expressions, we used the Spearman correlation.

All computations were performed in the $\mathrm{R}$ statistical environment ( $\mathrm{R}$ Core Team, 2014). Both lasso regularized and standard Cox regressions were performed by using $\mathrm{R}$ packages, namely glmnet (with parameters alpha $=1$ and family = "cox") and survival, respectively.

\section{Data access}

The data that support the findings of this study are available from https://www.ebi.ac.uk/ega/, but restrictions apply to the availability of these data, as these were used under license for the current study. Thus, these data are not publicly available. However, these data are available from the authors upon reasonable request and with permission of the Data Access Committee.

\section{Results}

\section{Development of a miRNA prognostic signature for TNBC patients}

The entire set of approximately 850 miRNAs was analyzed to develop a prognostic signature in the training set. One subject diagnosed with grade I was removed from our analysis due to its low quantity.

By performing the lasso regularized Cox regression analysis, we identified four miRNAs (two of them were putative) as being associated with overall survival in TNBC, namely miR-221 (probe ID: A_25_P00010690), miR-1305 (probe ID: A_25_P00015133), miR-11624 (probe ID: CRINCR2000004678, putative miRNA), and miR-10055 (probe ID: CRINCR2000004642, putative miRNA). We contacted the authors of the original study (Dvinge et al., 2013), who provided us with the probe sequences of the two putative miRNAs. Then, we re-annotated them by mapping the probe sequences to the human genome version hg38 by BLAT (Kent, 2002). The putative microRNAs miR-11624 and miR-10055 mapped to (with $100 \%$ alignment) the previously annotated miR-4708 and an exon of gene RMDN2 (regulator of microtubule dynamics 2), respectively. Therefore, our prognostic signature is composed of three microRNAs and one gene that codes for a protein, specifically miR-221, miR-1305, miR-4708, and RMDN2. Next, a prognostic model composed of these three miRNAs and the RMDN2 gene was constructed by using the standard Cox proportional hazard model. Associated coefficients and hazard ratios obtained in both univariate and multivariate (including clinical covariates) Cox proportional hazard models are described in Table 2. The Kaplan-Meier curve discrimi- 
Table 2 - Univariate and multivariate analyses of the four-biomarker signature. Univariate and multivariate analyses were performed based on the Cox regression model. CI: confidence interval.

\begin{tabular}{|c|c|c|c|c|}
\hline \multirow[b]{3}{*}{ Variables } & \multicolumn{4}{|c|}{ Training set } \\
\hline & \multicolumn{2}{|c|}{ Univariate analysis } & \multicolumn{2}{|c|}{ Multivariate analysis } \\
\hline & Hazard ratio $(95 \% \mathrm{CI})$ & $p$-value & Hazard ratio $(95 \% \mathrm{CI})$ & $p$-value \\
\hline Age at diagnosis & $1.12(0.85-1.47)$ & 0.407 & $1.12(0.70-1.80)$ & 0.642 \\
\hline Tumor grade (II/III) & $3.00(0.94-9.64)$ & 0.065 & $2.59(0.79-8.50)$ & 0.116 \\
\hline Tumor size & $1.27(1.07-1.50)$ & 0.006 & $1.06(0.88-1.27)$ & 0.540 \\
\hline Presence of nodes & $1.44(1.21-1.71)$ & $<0.001$ & $1.35(1.11-1.64)$ & 0.002 \\
\hline Menopausal status (pre/pos) & $1.04(0.60-1.83)$ & 0.883 & $1.30(0.46-3.66)$ & 0.623 \\
\hline \multirow[t]{3}{*}{ Four-biomarker signature } & $0.29(0.16-0.52)$ & $<0.001$ & $0.32(0.17-0.59)$ & $<0.001$ \\
\hline & \multicolumn{4}{|c|}{ Validation set } \\
\hline & \multicolumn{2}{|c|}{ Univariate analysis } & \multicolumn{2}{|c|}{ Multivariate analysis } \\
\hline Variables & Hazard ratio $(95 \% \mathrm{CI})$ & $p$-value & Hazard ratio $(95 \% \mathrm{CI})$ & $p$-value \\
\hline Age at diagnosis & $1.27(0.88-1.85)$ & 0.207 & $1.38(0.74-2.65)$ & 0.306 \\
\hline Tumor grade (II/III) & $2.73(0.37-20.22)$ & 0.327 & $2.08(0.27-16.09)$ & 0.484 \\
\hline Tumor size & $1.42(0.98-2.05)$ & 0.065 & $1.35(0.92-1.97)$ & 0.124 \\
\hline Presence of nodes & $1.51(0.98-2.30)$ & 0.059 & $1.62(0.96-2.72)$ & 0.071 \\
\hline Menopausal status (pre/pos) & $0.68(0.52-2.73)$ & 0.675 & $0.67(0.17-2.73)$ & 0.579 \\
\hline Four-biomarker signature & $0.39(0.14-1.04)$ & 0.059 & $0.32(0.11-0.91)$ & 0.033 \\
\hline
\end{tabular}

nating subjects classified with good or poor prognosis (log-rank test $p<0.001)$ in the training set is shown in Figure $2 \mathrm{~A}$. The four-biomarker signature (Table 2 ) is indeed statistically associated with overall survival time in TNBC even after inclusion of clinicopathological covariates (univariate: $\mathrm{HR}=0.29,95 \%$ CI: $0.16-0.52, p<0.001$; multivariate: HR $=0.32,95 \% \mathrm{CI}: 0.17-0.59, p<0.001)$.

Wilcoxon signed-rank tests showed that all four biomarkers (miR-221: $p<0.001$, miR-1305: $p<0.001$, miR4708: $p<0.001$, and RMDN2: $p<0.001)$ are significantly overexpressed in patients classified with good prognosis in the training set (Figure 3A).

\section{Validation of the four-biomarker signature in a test set}

The Cox proportional hazard model obtained in the training set was applied to 65 subjects of the testing set and validated. The Kaplan-Meier curves are shown in Figure 2B (log-rank test $p=0.050)$. Hazard ratios and respective $p$-values of both univariate and multivariate Cox proportional
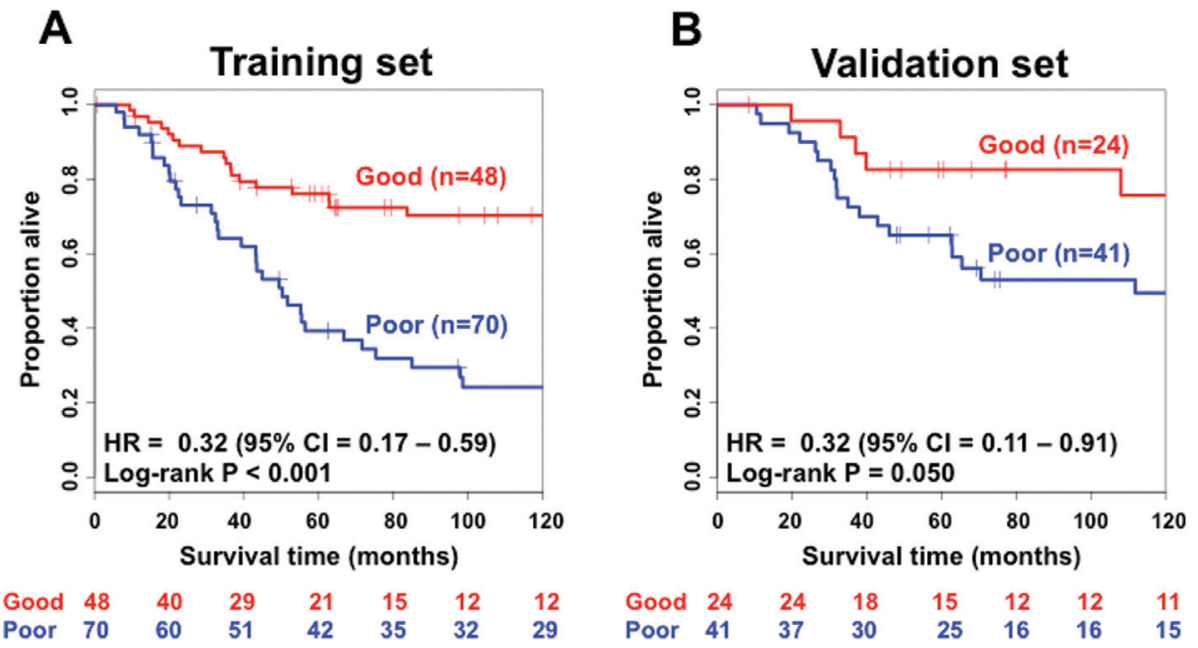

Figure 2 - Kaplan-Meier analysis showing that the four-biomarker signature is associated with survival in triple negative breast cancer. (A) Kaplan-Meier curve of the four-biomarker signature in the training set. (B) Kaplan-Meier curve of the four-biomarker signature in the validation set. $\mathrm{CI}=$ confidence interval; $\mathrm{HR}=$ hazard ratio. $\mathrm{HR}$ and $95 \% \mathrm{CI}$ were estimated by multivariate Cox regression with age at diagnosis, grade, the presence of nodes, and menopausal status included as covariates. The $p$-value was obtained by the log-rank test of the Kaplan-Meier curve. 
(A)

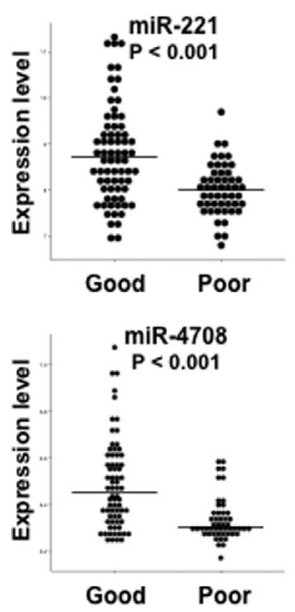

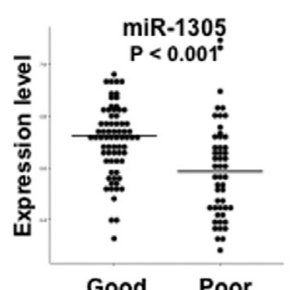

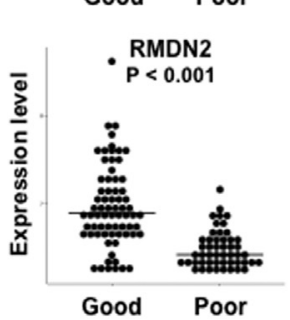

(B)

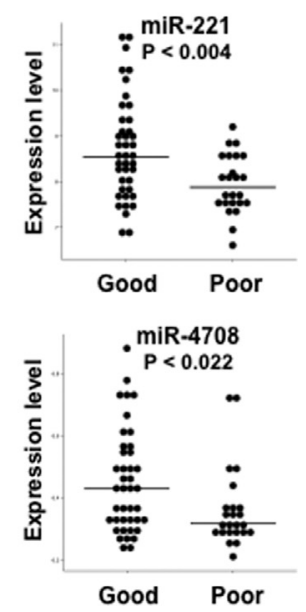

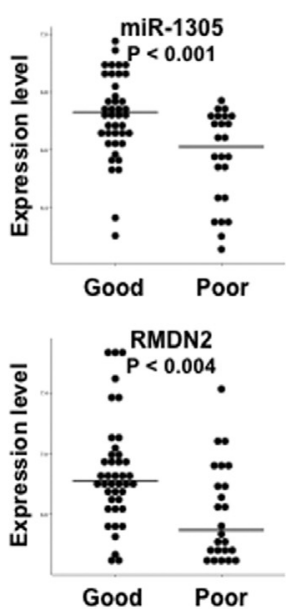

Figure 3 - Expression of miR-221, miR-1305, miR-4708, and RMDN2 between good and poor prognosis in the (A) training and (B) validation sets. Horizontal bars represent the median. All genes are statistically overexpressed in patients with a good prognosis at a $p$-value threshold of 0.05 .

hazard models are shown in Table 2. The four-biomarker signature is an independent prognostic factor (univariate: $\mathrm{HR}=0.39,95 \%$ CI: $0.14-1.04, p<0.059$; multivariate: HR $=0.39,95 \%$ CI: $0.14-1.04, p=0.033)$ after inclusion of the covariates. Subgroups of patients with postmenopausal status (Figure 4B - HR $=0.19 ; 95 \% \mathrm{CI}=0.04-0.90 ; p=0.016$ ), node negative status (Figure $4 \mathrm{C}-\mathrm{HR}=0.12 ; 95 \% \mathrm{CI}=0.01$ $-1.04 ; p=0.026)$, and a tumor size greater than the median, i.e., $2 \mathrm{~cm}$ (Figure $4 \mathrm{~F}-\mathrm{HR}=0.21 ; 95 \% \mathrm{CI}=0.05-0.81 ; p=$ 0.021 ) also showed that the four-biomarker signature was statistically associated with overall survival. Subgroups comprising premenopausal status (Figure 4A $-\mathrm{HR}=0.54$; $95 \% \mathrm{CI}=0.09-3.21 ; p=0.966$ ), node positive status (Figure $4 \mathrm{D}-\mathrm{HR}=0.78 ; 95 \% \mathrm{CI}=0.25-2.47 ; p=0.543)$, and a tumor size smaller than $2 \mathrm{~cm}$ (Figure 4E - HR $=0.60 ; 95 \%$ $\mathrm{CI}=0.12-2.86 ; p=0.535)$ do not present statistical evidence of associations between the four-biomarker signature and survival outcome at a $p$-value threshold of 0.05 .

Wilcoxon signed-rank tests showed that all four biomarkers (miR-221: $p=0.004, \operatorname{miR}-1305: p=0.001$, miR4708: $p=0.022$, and RMDN2: $p=0.004$ ) are also significantly overexpressed in patients classified with good prognosis in the validation set, confirming the results obtained in the training set (Figure 3B).

To confirm that indeed all four biomarkers are essential for classification into good or poor prognoses, we performed the following experiment: four competing threebiomarker signatures were designed by deleting one of the four genes from the set. Then, we repeated the survival analysis for each of these three-biomarker signatures. The results showed that none of the three-gene signatures was statistically associated with overall survival in the testing data set, confirming that all four biomarkers are, in fact, necessary (Figure S1).

Next, we analyzed the gene expression patterns between the identified miRNAs and their known target genes.
We identified a statistically significant negative association between miR-221 and $p 27$ (Spearman correlation $=-0.34 ; p$ $<0.005$ ), but not between miR-221 and $c$-kit (Spearman correlation $=0.18 ; p$-value $=0.158), \operatorname{miR}-1305$ and $R U N X 2$ $($ Spearman correlation $=-0.14 ; p$-value $=0.282)$, $\operatorname{miR}-4708$ and SMAD1 (Spearman correlation $=-0.14 ; p$-value $=$ 0.250 ), and miR-4708 and SMAD4 (Spearman correlation $=$ $0.18 ; p$-value $=0.158)$. We also constructed Kaplan-Meier curves for the five target genes. Figure 5 shows that all five target genes are also associated with TNBC overall survival. Figure 6A shows the heatmaps for both the four biomarkers and Figure 6B for their target genes (p27, c-kit, RUNX2, $S M A D 1$, and SMAD4) in the 65 individuals composing the validation set. To verify whether the categorizations as good or poor prognosis by the four-biomarker set are similar to the ones obtained by each one of the five target genes, we calculated the Spearman correlation coefficient. As results, we obtained the following: $p 27$ (Spearman correlation $=1$; $p$-value $<0.001), c$ - $k$ it $($ Spearman correlation $=0.80 ; p$-value $<0.001), R U N X 2$ (Spearman correlation $=0.81 ; p$-value $<$ $0.001), S M A D 1$ (Spearman correlation $=1 ; p$-value $<0.001)$, and SMAD4 (Spearman correlation $=1 ; p$-value $<0.001)$. In other words, the classification of TNBC patients into low or high risk obtained by the four-biomarker is very similar to the classification obtained by each target gene independently.

\section{Discussion}

By analyzing a large TNBC cohort, we identified a four-biomarker signature composed of miR-221, miR-1305, miR-4708, and RMDN2 in a training set and then confirmed their association with prognosis in a validation set.

miR-221 has been associated with several cancers, such as thyroid papillary (Visone et al., 2007), liver (Pineau et al., 2010), and prostate cancers (Fornari et al., 2008). miR-221 directly interacts with cyclin-dependent kinase in- 

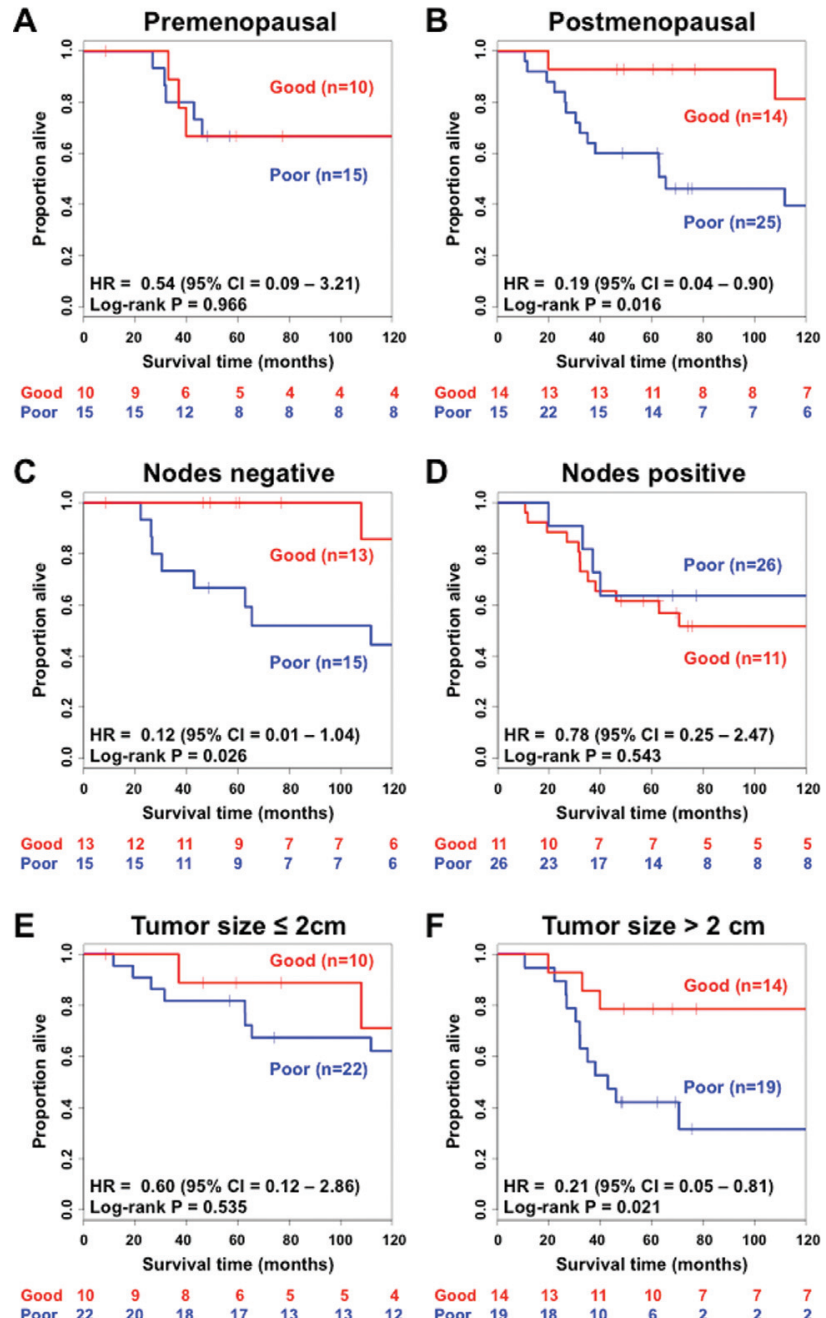

Figure 4 - Kaplan-Meier analysis of overall survival in subgroups of triple-negative breast cancer patients in the validation set. (A) Premenopausal patients; (B) postmenopausal patients; (C) patients without nodes identified; (D) patients with nodes; (E) patients with a tumor size of $2 \mathrm{~cm}$ or less; (F) patients with tumor size greater than $2 \mathrm{~cm}$. Hazard ratios and confidence intervals were obtained by multivariate Cox regression with age at diagnosis, tumor grade, tumor size, and presence of nodes status as covariates. $P$-values were obtained by log-rank tests for the Kaplan-Meier curves. $\mathrm{HR}=$ hazard ratio; $\mathrm{CI}=$ confidence interval.

hibitors $\mathrm{CDKN} 1 \mathrm{~B} / p 27$ and $\mathrm{CDKN} 1 \mathrm{C} / p 57$ by binding to their mRNA 3'UTR (le Sage et al., 2007; Visone et al., 2007; Fornari et al., 2008; Pineau et al., 2010). Galardi et al. (2007) and Visone et al. (2007) showed that the expression levels of miR-221 and $p 27$ are negatively correlated, which was also confirmed in our TNBC dataset. Thus, the downregulation of miR-221 in the group classified with poor prognosis might lead to increased $p 27$ expression.

P27 is a negative regulator of cell cycle progression, and the loss of this protein is often observed in several cancers (le Sage et al., 2007; Visone et al., 2007; Fornari et al., 2008; Pineau et al., 2010). The increased p27 expression through miR-221 down-regulation in patients classified with poor prognosis might induce cell cycle arrest, resulting in resistance to chemotherapy (chemotherapy is useful in highly proliferative cancer cells, but it is not effective in quiescent cells or slow-cycling). Cancer stem cells, which are responsible for cancer metastasis and recurrence, are generally quiescent or slow-cycling and resistant to conventional chemoand radio-therapies (Yoshida and Saya, 2016). Zou et al. (2011) reported that p27 and p57 control hematopoietic stem cells dormancy, while Besson et al. (2007) showed an association between p27 and bronchioalveolar stem cell expansion. Moreover, it is also known that p27 prevents the activation of RhoA (Besson et al., 2004; Wang and Lee, 2014) and that the inactivation of the RhoA-ROCK pathway enhances cancer stem cell propagation (Ohata et al., 2012; Tilson et al., 2015).

Another possible pathway influenced by miR-221 and also related to tumorigenesis is angiogenesis. Endothelial cells transfected in vitro with miR-221 have inhibited tube formation, migration, and wound healing properties (Poliseno et al., 2006). The underlying mechanism involves the down-regulation of the protein c-kit, a receptor for stem cell factor, without affecting the mRNA level, suggesting a post-transcriptional regulation (Poliseno et al., 2006). Indeed, even in our TNBC data set, we did not identify the correlation between miR-221 and $c$-kit expression. In hematopoietic progenitor cells, miR-221 reduces $c$-kit expression and thus reduces cell proliferation (Felli et al., 2005). Overexpression of miR-221 indirectly reduces the expression of endothelial nitric oxide synthase (NOS) in Dicer siRNA-transfected cells (Suarez et al., 2007). Nitric oxide is a crucial regulator for endothelial cell growth, migration, vascular remodeling, and angiogenesis (Zeiher, 1996). Recently, it was demonstrated that endothelial NOS plays a crucial role in the mobilization and functional activity of stem and progenitor cells (Aicher et al., 2003; Iwakura et al., 2003; Landmesser et al., 2004).

Changes in the miR-1305 expression are associated with tumorigenesis in several tissues (Niyazi et al., 2011; Shah et al., 2013; Tormo et al., 2015). RUNX2 is a direct target of miR-1305 (Chen and Liu, 2017), and its up-regulation is associated with a variety of cancer tissues (Brubaker et al., 2003; Kayed et al., 2007; Endo et al., 2008). More specifically, in breast cancer, Runx 2 has been demonstrated to promote bone metastasis (Javed et al., 2005; Li et al., 2015). The inhibition of miR-1305 expression in TNBC patients may lead to an increase in Runx2 expression via a post-transcriptional mechanism (because we did not identify the correlation between them) that promotes breast cancer aggressiveness.

Overexpression of miR-4708 directly inhibits SMAD1 and SMAD4 gene expression (Kato et al., 2014). The SMAD family is a group of transcription factors coding regulatory genes that mediate the TGF- $\beta$ pathway, which controls the cell cycle and growth (Massagué, 2000; Derynck et al., 2001). The TGF- $\beta$ pathway can inhibit cell proliferation by activating receptor-regulator SMADs (SMAD1, 2, 3, 5, and 8 ), which activate SMAD4. These molecules are then transferred to the nucleus to control gene expression (Shi and Massague, 2003). 
Consistent with the tumor inhibitory role of the TGF- $\beta$ pathway, the association between deregulation of SMADs and tumor proliferation has been found in different cell types. Increased BMPR-IB (a protein of TGF- $\beta$ pathway) expression leads to a deregulated SMAD1 activity, which was already reported to be associated with an increase in breast cancer progression (Helms et al., 2005). Inactivating mutations in SMAD4 have been found in different tumor types (Hahn et al., 1996; Schutte et al., 1996; Miyaki et al., 1999), including breast cancers (Levy and Hill, 2005; Deckers et al., 2006). Moreover, silencing or knockout of SMAD4 promotes cell proliferation by abrogating the TGF- $\beta$ pathway (Levy and Hill, 2005; Deckers et al., 2006).

Aside from the inhibitory characteristic of the TGF- $\beta$ pathway on cell growth, this pathway is also central to another contradictory role, metastasis (Derynck et al., 2001). Evidence suggests that the down-regulation of SMAD4 reduces metastasis in breast cancer cells (Deckers et al., 2006).

Thus, these findings suggest the following hypothesis: down-regulation of miR-4708 increases $S M A D$ expression, which, in turn, activates the TGF- $\beta$ pathway. TGF- $\beta$ pathway activation, then, could lead to increased metastatic behavior. Since we did not identify the correlation between mir-4708 and SMAD1 neither between mir-4708 and $S M A D 4$, we believe they may be regulated by a posttranscriptional mechanism.
Finally, the $R M D N 2$ gene is known to code proteins that bind and regulate microtubule growth. Its mutants are associated with defective chromosome segregation (Oishi et al., 2007; Law et al., 2015). During anaphase, when the sister chromatids usually move in opposite directions, in RMDN2 mutants, chromatids do not segregate; they become stretched and cut at the end of cell division (Oishi et al., 2007). A genome-wide association analysis suggested a potential relationship between the RMDN2 3'UTR and increased susceptibility to malignant melanoma (Law et al., 2015).

In summary, all four biomarkers are associated with cell cycle control and growth, pathways that are intimately related to cancer development and progression. The presented scenario supports the hypothesis that the down-regulation of these four biomarkers may be leading to more aggressive and faster-growing tumors in patients classified with a poor prognosis.

By analyzing the five genes that are targets of the three miRNAs (Figure 5), we noticed that the Kaplan-Meier curves are very similar. This can be explained by the fact that these five genes are highly correlated. Notice that in the heatmap of Figure $6 \mathrm{~B}$, there are two sets of genes: one composed of SMAD1, SMAD4, and p27, and the second one composed of $R U N X 2$ and $c$-kit. Within each set, the genes are positively correlated $(p<0.05$ for all pairwise Spearman
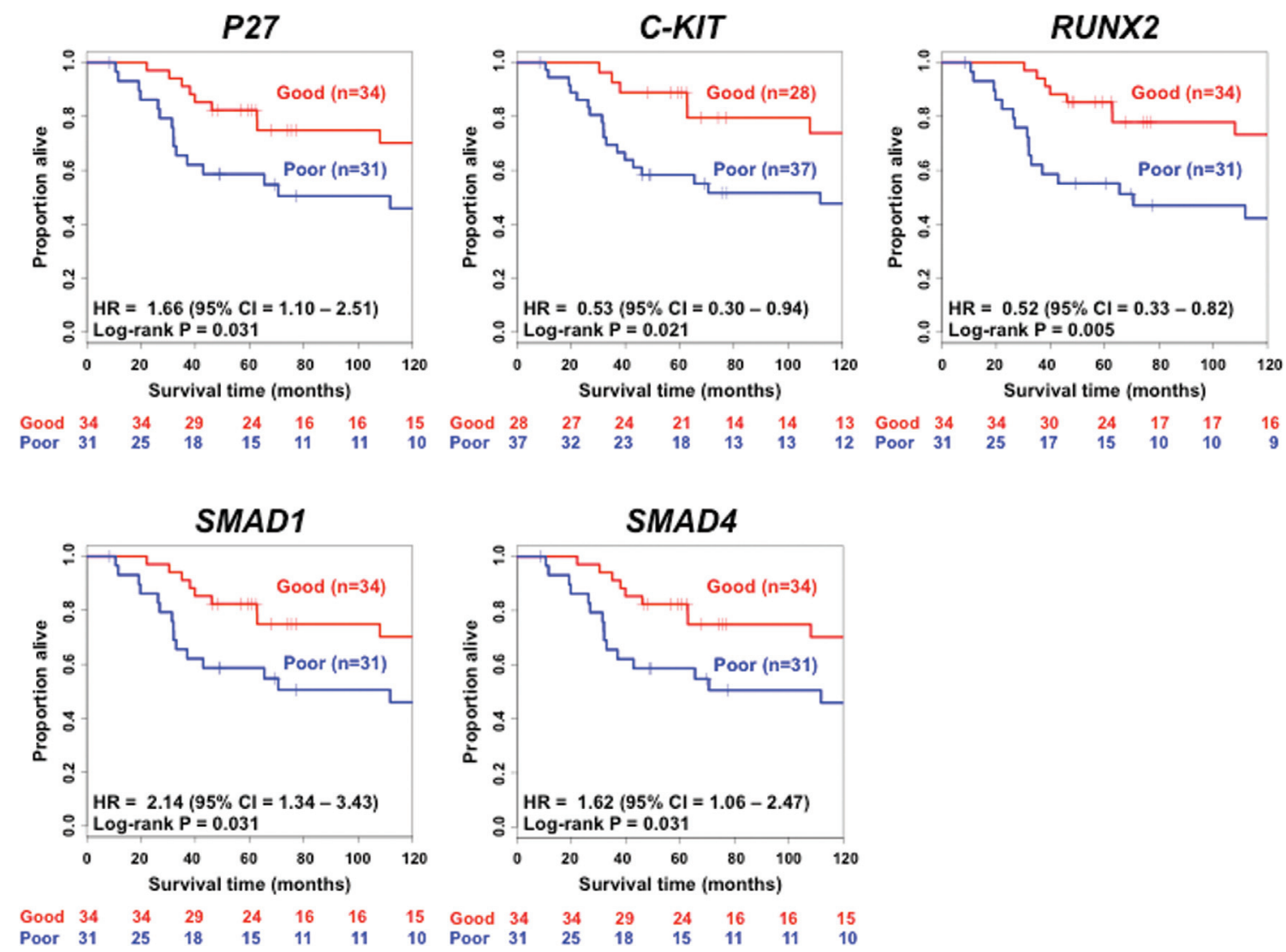

Figure 5 - Kaplan-Meier analysis showing that the five target genes are associated with survival in triple negative breast cancer. The $p$-value is obtained by the log-rank test of the Kaplan-Meier curve. 
correlations within the set), while between sets, they are negatively correlated ( $p<0.05$ for all pairwise Spearman correlations between sets). No correlation was observed among the four biomarkers ( $p>0.05$ for all pairwise Spearman correlations) (Figure 6A). Interestingly, the classifications obtained by the four-biomarker set and each one of the five target genes are very similar (high correlation). This means that, although there is no correlation between the miRNA and expression of its respective target gene, the cooperative indirect regulation of the four biomarkers on the target genes might affect the TNBC malignancy (notice that in Figure S1 all four biomarkers were necessary for a proper classification).

Although these results indicate that the four-biomarker signature described here is statistically associated with TNBC survival outcome, it would be worthwhile to validate them in other independent cohorts. However, only limited comparison with published data is possible due to at least two reasons: (i) the lack of large miRNA TNBC datasets and (ii) the absence of these four biomarkers in other studies. For example, Lowery et al. (2009) and Mattie et al. (2006) analyzed miRNAs in small sets composed of 29 and 20 breast cancer tumors, respectively. Alternatively, Farazi et al. (2011), Gasparini et al. (2014), and Raju et al. (2014) provided large sets composed of 185, 219, and 587 patients of diverse types of breast cancer, respectively, but none of their datasets have the four biomarkers that we identified here.

We also tried validation by using the TCGA data set. We downloaded all the miRNA/mRNA data of 1,099 individuals diagnosed with breast cancer from the TCGA

\section{(A)}

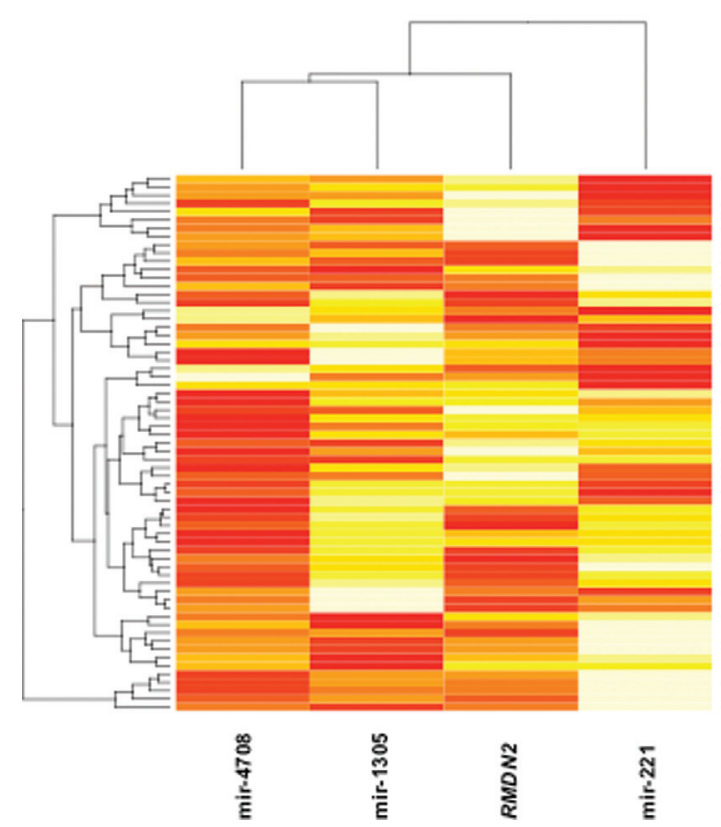

webpage. Among them, 113 were diagnosed with TNBC. We applied our Cox proportional hazard model obtained in the training set to these 113 subjects. The Kaplan-Meier curves presented a log-rank test $p$-value equal to 0.72 . In other words, it was not possible to confirm our results in the TCGA data set. We have at least two possible explanations for this negative result. The first one is the low number of deaths in the TCGA data set (only 13 individuals out of 113, i.e., $\sim 11.5 \%$ ). By considering a low number of deaths, it is challenging to identify differences between the KaplanMeier curves, even if they exist. For comparison, notice that in the data set we used for our analyses (European Genome-phenome Archive - EGpA), the proportions of deaths are $46.7 \%$ and $53.3 \%$ in the training and validation data sets, respectively (see Table 1). The second explanation is based on the short follow-up length of the TCGA data set. In Figure 7, we show the boxplots regarding the follow-up lengths for people considered alive and dead in both EGpA and TCGA data sets. Notice that there is no statistical difference in terms of time to death between individuals that died in the EGpA (average of 39.44 months) and TCGA (average of 45.69 months) data sets ( $p=0.973$, Wilcoxon rank test). However, when we analyzed the time lengths for the last follow-up of people who survived (or did not die yet), we notice that EGpA has a much longer follow-up (average of 118.55 months) than TCGA (average of 21.12 months) ( $p$-value $<$ 0.001 , Wilcoxon rank test). In other words, to better characterize the outcomes of individuals from the TCGA data set, we believe that a more extended period of follow-up is necessary.
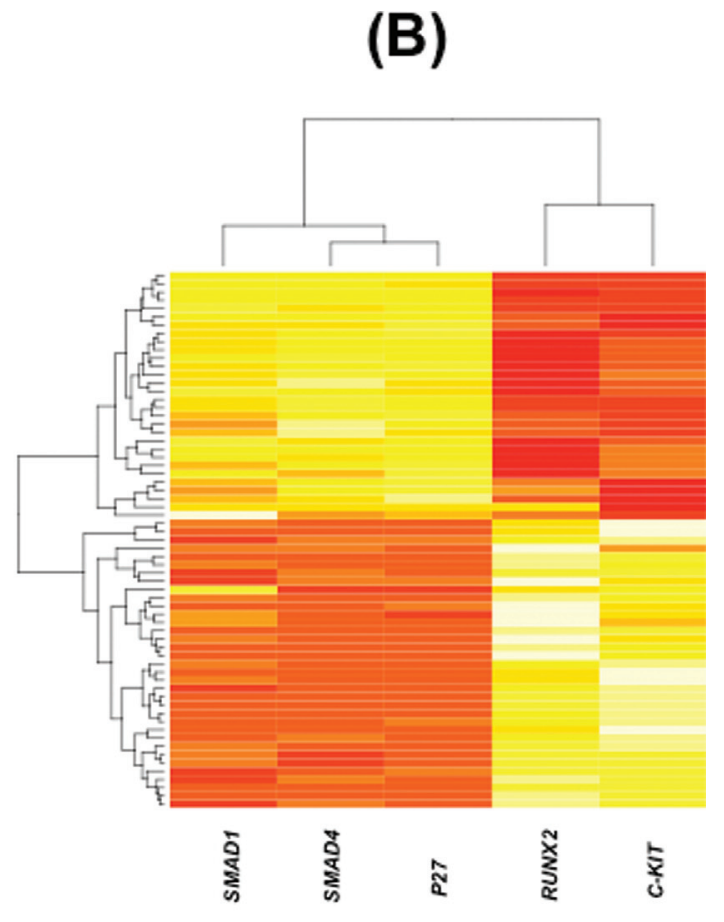

Figure 6 - Gene expression heatmaps. (A) For the four prognostic biomarkers and (B) the five genes targets of the three miRNAs. In panel (A), the four biomarkers are not correlated, while in panel (B) there are two sets of genes: one composed of genes SMAD1, SMAD4, and p27, and the second set composed of RUNX2 and c-kit. Genes within the sets are positively highly correlated, while between sets, they are negatively highly correlated. 


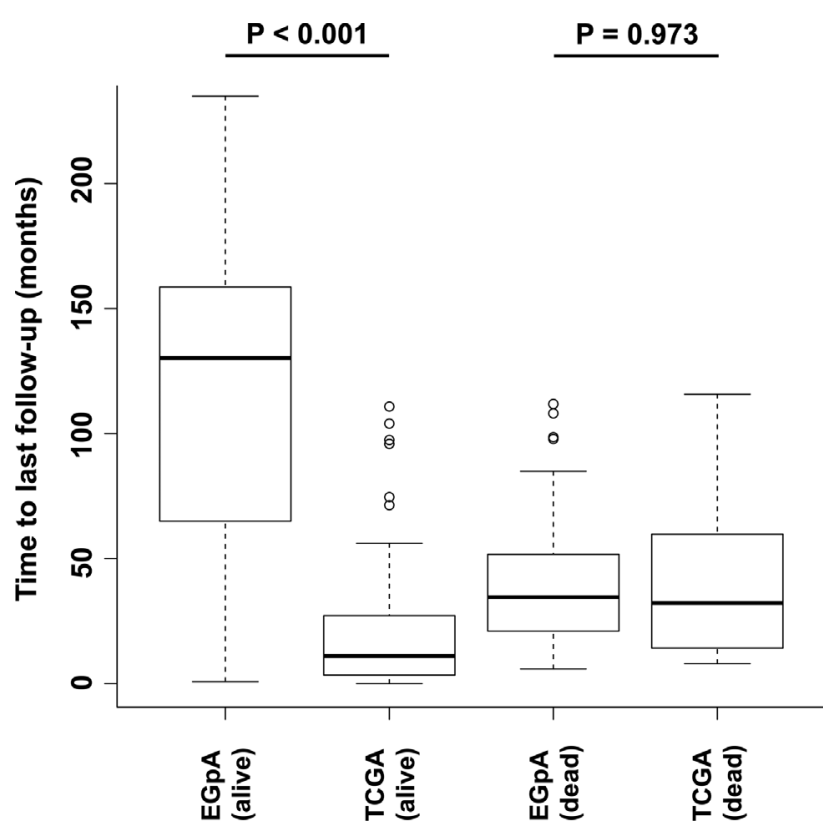

Figure 7 - Time lengths for the last follow-ups. There is no statistical difference in terms of time to death between individuals that died in the EGpA (average of 39.44 months) and TCGA (average of 45.69 months) data sets ( $p=0.973$, Wilcoxon rank test). However, when we analyzed the time length for the last follow-up of people who did not die, we noticed that EGpA has a much longer follow-up (average of 118.55 months) than TCGA (average of 21.12 months) ( $p$-value $<0.001$, Wilcoxon rank test).

The four-biomarker signature is statistically associated with the overall survival of TNBC patients. These results may aid in the development of better methods to predict prognosis or choose therapies for the management of TNBC patients.

\section{Acknowledgments}

The authors would like to thank Anna Git for providing information regarding the probe sequences identified in this work. This study was supported by FAPESP (\#2015/01587-0, \#2016/13422-9, \#2018/21934-5), CNPq (304876/2016-0), JICA, Alexander von Humboldt Foundation, and Newton Fund.

\section{Conflict of Interest}

The authors declare that they have no competing interests.

\section{Author Contributions}

$\mathrm{AN}$ and AF made substantial contributions to conception, design, and analysis. FA and AN interpreted the results. FA pre-processed the data. NG and AF directed the work. All of the authors have been involved in drafting the manuscript and revising it critically for relevant intellectual content. All of the authors read and approved the final manuscript.

\section{References}

Aicher A, Heeschen C, Mildner-Rihm C, Urbich C, Ihling C, Technau-Ihling K, Zeiher AM and Dimmeler S (2003) Essential role of endothelial nitric oxide synthase for mobilization of stem and progenitor cells. Nat Med 9:1370.

Ariazi EA, Ariazi JL, Cordera F and Jordan VC (2006) Estrogen receptors as therapeutic targets in breast cancer. Curr Top Med Chem 6:181-202.

Bartel DP (2004) MicroRNAs: Genomics, biogenesis, mechanism, and function. Cell 116:281-297.

Besson A, Gurian-West M, Schmidt A, Hall A and Roberts JM (2004) p27kip1 modulates cell migration through the regulation of rhoa activation. Genes Dev 18:862-876.

Besson A, Hwang HC, Cicero S, Donovan SL, Gurian-West M, Johnson D, Clurman BE, Dyer MA and Roberts JM (2007) Discovery of an oncogenic activity in p27kip1 that causes stem cell expansion and a multiple tumor phenotype. Genes Dev 21:1731-1746.

Blows FM, Driver KE, Schmidt MK, Broeks A, Van Leeuwen FE, Wesseling J, Cheang MC, Gelmon K, Nielsen TO, Blomqvist C et al. (2010) Subtyping of breast cancer by immunohistochemistry to investigate a relationship between subtype and short and long term survival: A collaborative analysis of data for 10,159 cases from 12 studies. PLoS Med 7:e1000279.

Brubaker KD, Vessella RL, Brown LG and Corey E (2003) Prostate cancer expression of runt-domain transcription factor runx2, a key regulator of osteoblast differentiation and function. Prostate 56:13-22.

Cascione L, Gasparini P, Lovat F, Carasi S, Pulvirenti A, Ferro A, Alder H, He G, Vecchione A, Croce CM et al. (2013) Integrated microRNA and mRNA signatures associated with survival in triple negative breast cancer. PloS One 8:e55910.

Chen Z and Liu HL (2017) Restoration of mir-1305 relieves the inhibitory effect of nicotine on periodontal ligament-derived stem cell proliferation, migration, and osteogenic differentiation. J Oral Pathol Med 46:313-320.

Curtis C, Shah SP, Chin SF, Turashvili G, Rueda OM, Dunning MJ, Speed D, Lynch AG, Samarajiwa S, Yuan Y et al. (2012) The genomic and transcriptomic architecture of 2,000 breast tumours reveals novel subgroups. Nature 486:346-352.

Dawood S, Broglio K, Buzdar AU, Hortobagyi GN and Giordano SH (2009) Prognosis of women with metastatic breast cancer by her 2 status and trastuzumab treatment: An institutional-based review. J Clin Oncol 28:92-98.

Deckers M, van Dinther M, Buijs J, Que I, Lowik C, van der Pluijm G and Dijke P (2006) The tumor suppressor smad4 is required for transforming growth factor $\beta$-induced epithelial to mesenchymal transition and bone metastasis of breast cancer cells. Cancer Res 66:2202-2209.

Derynck R, Akhurst RJ and Balmain A (2001) TGF- $\beta$ signaling in tumor suppression and cancer progression. Nat Gen 29:117-129.

Dvinge H, Git A, Graf S, Salmon-Divon M, Curtis C, Sottoriva A, Zhao Y, Hirst M, Armisen J, Miska EA et al. (2013) The shaping and functional consequences of the microRNA landscape in breast cancer. Nature 497:378.

Endo T, Ohta K and Kobayashi T (2008) Expression and function of cbfa-1/runx2 in thyroid papillary carcinoma cells. J Clin Endocrinol Metab 93:2409-2412. 
Farazi TA, Horlings HM, Ten Hoeve J, Mihailovic A, Halfwerk H, Morozov P, Brown M, Hafner M, Reyal F, van Kouwenhove $\mathrm{M}$ et al. (2011) MicroRNA sequence and expression analysis in breast tumors by deep sequencing. Cancer Res 71:4443-4453.

Felli N, Fontana L, Pelosi E, Botta R, Bonci D, Facchiano F, Liuzzi F, Lulli V, Morsilli O, Santoro S et al. (2005) MicroRNAs 221 and 222 inhibit normal erythropoiesis and erythroleukemic cell growth via kit receptor downmodulation. Proc Natl Acad Sci U S A 102:18081-18086.

Fornari F, Gramantieri L, Ferracin M, Veronese A, Sabbioni S, Calin G, Grazi G, Giovannini C, Croce C, Bolondi L et al. (2008) Mir-221 controls cdkn1c/p57 and cdkn1b/p27 expression in human hepatocellular carcinoma. Oncogene 27:5651-5661.

Friedman J, Hastie T and Tibshirani R (2010) Regularization paths for generalized linear models via coordinate descent. J Stat Softw 33:1.

Galardi S, Mercatelli N, Giorda E, Massalini S, Frajese GV, Ciafre' SA and Farace MG (2007) mir-221 and mir-222 expression affects the proliferation potential of human prostate carcinoma cell lines by targeting p27kip1. J Biol Chem 282:23716-23724.

Gasparini P, Cascione L, Fassan M, Lovat F, Guler G, Balci S, Irkkan C, Morrison C, Croce CM, Shapiro CL et al. (2014) MicroRNA expression profiling identifies a four microRNA signature as a novel diagnostic and prognostic biomarker in triple negative breast cancers. Oncotarget 5:1174.

Gonzalez-Angulo AM, Hennessy BT, Broglio K, Meric-Bernstam F, Cristofanilli M, Giordano SH, Buchholz TA, Sahin A, Singletary SE, Buzdar AU et al. (2007) Trends for inflammatory breast cancer: is survival improving? Oncologist 12:904-912.

Hahn SA, Schutte M, Hoque AS, Moskaluk CA, Da Costa LT, Rozenblum E, Weinstein CL, Fischer A, Yeo CJ, Hruban RH et al. (1996) DPC4, a candidate tumor suppressor gene at human chromosome 18q21.1. Science 271:350-353.

Helms MW, Packeisen J, August C, Schittek B, Boecker W, Brandt BH and Buerger H (2005) First evidence supporting a potential role for the bmp/smad pathway in the progression of oestrogen receptor- positive breast cancer. J Pathol 206:366-376.

Iwakura A, Luedemann C, Shastry S, Hanley A, Kearney M, Aikawa R, Isner JM, Asahara T and Losordo DW (2003) Estrogen-mediated, endothelial nitric oxide synthase-dependent mobilization of bone marrow-derived endothelial progenitor cells contributes to reendothelialization after arterial injury. Circulation 108:3115-3121.

Iwase H, Kurebayashi J, Tsuda H, Ohta T, Kurosumi M, Miyamoto K, Yamamoto Y and Iwase T (2010) Clinicopathological analyses of triple negative breast cancer using surveillance data from the registration committee of the Japanese Breast Cancer Society. Breast Cancer 17:118-124.

Javed A, Barnes GL, Pratap J, Antkowiak T, Gerstenfeld LC, Van Wijnen AJ, Stein JL, Lian JB and Stein GS (2005) Impaired intranuclear trafficking of runx 2 (aml3/cbfa1) transcription factors in breast cancer cells inhibits osteolysis in vivo. Proc Natl Acad Sci U S A 102:1454-1459.

Kato RB, Roy B, De Oliveira FS, Ferraz EP, De Oliveira PT, Kemper AG, Hassan MQ, Rosa AL and Beloti MM (2014) Nanotopography directs mesenchymal stem cells to osteo- blast lineage through regulation of microrna-smad-bmp-2 circuit. J Cell Physiol 229:1690-1696.

Kayed H, Jiang X, Keleg S, Jesnowski R, Giese T, Berger M, Esposito I, Lohr M, Friess H and Kleeff J (2007) Regulation and functional role of the runt-related transcription factor-2 in pancreatic cancer. Br J Cancer 97:1106.

Kent WJ (2002) Blat, the blast-like alignment tool. Genome Res 12:656-664.

Landmesser U, Engberding N, Bahlmann FH, Schaefer A, Wiencke A, Heineke A, Spiekermann S, Hilfiker-Kleiner D, Templin C, Kotlarz D et al. (2004) Statin-induced improvement of endothelial progenitor cell mobilization, myocardial neovascularization, left ventricular function and survival after experimental myocardial infarction requires endothelial nitric oxide synthase. Circulation 110:1933-1939.

Law MH, Bishop DT, Lee JE, Brossard M, Martin NG, Moses EK, Song F, Barrett JH, Kumar R, Easton DF et al. (2015) Genome-wide meta-analysis identifies five new susceptibility loci for cutaneous malignant melanoma. Nat Gen 47:987-995.

le Sage C, Nagel R, Egan DA, Schrier M, Mesman E, Mangiola A, Anile C, Maira G, Mercatelli N, Ciafre'SA et al. (2007) Regulation of the $\mathrm{p} 27$ kip 1 tumor suppressor by mir-221 and mir-222 promotes cancer cell proliferation. EMBO J 26:3699-3708.

Levy L and Hill CS (2005) Smad4 dependency defines two classes of transforming growth factor $\beta$ (TGF- $\beta$ ) target genes and distinguishes TGF- $\beta$-induced epithelial-mesenchymal transition from its antiproliferative and migratory responses. Mol Cell Biol 25:8108-8125.

Li XQ, Du X, Li DM, Kong PZ, Sun Y, Liu PF, Wang QS and Feng YM (2015) ITGBL1 is a Runx2 transcriptional target and promotes breast cancer bone metastasis by activating the TGF- $\beta$ signaling pathway. Cancer Res 75:3302-3313.

Lowery AJ, Miller N, Devaney A, McNeill RE, Davoren PA, Lemetre C, Benes V, Schmidt S, Blake J, Ball G et al. (2009) MicroRNA signatures predict estrogen receptor, progesterone receptor and her $2 /$ neu receptor status in breast cancer. Breast Cancer Res 11:R27.

Lu J, Getz G, Miska EA, Alvarez-Saavedra E, Lamb J, Peck D, Sweet-Cordero A, Ebert BL, Mak RH, Ferrando AA et al. (2005) MicroRNA expression profiles classify human cancers. Nature 435:834.

Mattie MD, Benz CC, Bowers J, Sensinger K, Wong L, Scott GK, Fedele V, Ginzinger D, Getts R and Haqq C (2006) Optimized high-throughput microRNA expression profiling provides novel biomarker assessment of clinical prostate and breast cancer biopsies. Mol Cancer 5:24.

Miyaki M, Iijima T, Konishi M, Sakai K, Ishii A, Yasuno M, Hishima T, Koike M, Shitara N, Iwama T et al. (1999) Higher frequency of smad4 gene mutation in human colorectal cancer with distant metastasis. Oncogene 18:3098-3103.

Niyazi M, Zehentmayr F, Niemoller OM, Eigenbrod S, Kretzschmar H, Schulze-Osthoff K, Tonn JC, Atkinson M, Mortl S and Belka C (2011) miRNA expression patterns predict survival in glioblastoma. Radiat Oncol 6:153.

Ohata H, Ishiguro T, Aihara Y, Sato A, Sakai H, Sekine S, Taniguchi H, Akasu T, Fujita S, Nakagama H et al. (2012) Induction of the stem-like cell regulator cd44 by rho kinase inhibition contributes to the maintenance of colon cancer-initiating cells. Cancer Res 72:5101-5110. 
Oishi K, Okano H and Sawa H (2007) Rmd-1, a novel microtubule-associated protein, functions in chromosome segregation in Caenorhabditis elegans. J Cell Biol 179:1149-1162.

Pineau P, Volinia S, McJunkin K, Marchio A, Battiston C, Terris B, Mazzaferro V, Lowe SW, Croce CM and Dejean A (2010) mir-221 overexpression contributes to liver tumorigenesis. Proc Natl Acad Sci U S A 107:264-269.

Place RF, Li LC, Pookot D, Noonan EJ and Dahiya R (2008) MicroRNA-373 induces expression of genes with complementary promoter sequences. Proc Natl Acad Sci U S A 105:1608-1613.

Poliseno L, Tuccoli A, Mariani L, Evangelista M, Citti L, Woods K, Mercatanti A, Hammond S and Rainaldi G (2006) MicroRNAs modulate the angiogenic properties of huvecs. Blood 108:3068-3071.

R Core Team (2014) The R Project for Statistical Computing, https://www.r-project.org/.

Raju R, Paul AM, Asokachandran V, George B, Radhamony L, Vinaykumar M, Girijadevi R and Pillai MR (2014) The triple-negative breast cancer database: An omics platform for reference, integration and analysis of triple-negative breast cancer data. Breast Cancer Res 16:490.

Risbridger GP, Davis ID, Birrell SN and Tilley WD (2010) Breast and prostate cancer: More similar than different. Nat Rev Cancer 10:205.

Schutte M, Hruban RH, Hedrick L, Cho KR, Nadasdy GM, Weinstein CL, Bova GS, Isaacs WB, Cairns P, Nawroz H et al. (1996) DPC4 gene in various tumor types. Cancer Res 56:2527-2530.

Shah AA, Leidinger P, Backes C, Keller A, Karpinski P, Sasiadek MM, Blin N and Meese E (2013) A set of specific miRNAs is connected with murine and human gastric cancer. Genes Chromosomes Cancer 52:237-249.

Shi Y and Massague J (2003) Mechanisms of TGF- $\beta$ signaling from cell membrane to the nucleus. Cell 113:685-700.

Siegel RL, Miller KD and Jemal A (2016) Cancer statistics, 2016. CA Cancer J Clin 66:7-30.

Suarez Y, Fernandez-Hernando C, Pober JS and Sessa WC (2007) Dicer dependent microRNAs regulate gene expression and functions in human endothelial cells. Circ Res 100:1164-1173.

The Cancer Genome Atlas Network (2012) Comprehensive molecular portraits of human breast tumors. Nature 490:61.

Tilson SG, Haley EM, Triantafillu UL, Dozier DA, Langford CP, Gillespie GY and Kim Y (2015) Rock inhibition facilitates in vitro expansion of glioblastoma stem-like cells. PLoS One 10:e132823.
Tormo E, Pineda B, Serna E, Guijarro A, Ribas G, Fores J, Chirivella E, Climent J, Lluch A and Eroles P (2015) MicroRNA profile in response to doxorubicin treatment in breast cancer. J Cell Biochem 116:2061-2073.

Vasudevan S, Tong Y and Steitz JA (2007) Switching from repression to activation: microRNAs can up-regulate translation. Science 318:1931-1934.

Visone R, Russo L, Pallante P, De Martino I, Ferraro A, Leone V, Borbone E, Petrocca F, Alder H, Croce CM et al. (2007) MicroRNAs (mir)-221 and mir-222, both overexpressed in human thyroid papillary carcinomas, regulate p27kip 1 protein levels and cell cycle. Endocr Relat Cancer 14:791-798.

Vogel CL, Cobleigh MA, Tripathy D, Gutheil JC, Harris LN, Fehrenbacher L, Slamon DJ, Murphy M, Novotny WF, Burchmore M et al. (2002) Efficacy and safety of trastuzumab as a single agent in first-line treatment of her2-overexpressing metastatic breast cancer. J Clin Oncol 20:719-726.

Wang HC and Lee WS (2014) Progesterone induces Rhoa inactivation in male rat aortic smooth muscle cells through upregulation of p27kip1. Endocrinology 155:4473-4482.

Yoshida GJ and Saya H (2016) Therapeutic strategies targeting cancer stem cells. Cancer Sci 107:5-11.

Zeiher AM (1996) Endothelial vasodilator dysfunction: pathogenetic link to myocardial ischaemia orepiphenomenon? Lancet 348:S10-S12.

Zeng Y, Yi R and Cullen BR (2003) MicroRNAs and small interfering RNAs can inhibit mRNA expression by similar mechanisms. Proc Natl Acad Sci U S A 100:9779-9784.

Zou P, Yoshihara H, Hosokawa K, Tai I, Shinmyozu K, Tsukahara F, Maru Y, Nakayama K, Nakayama KI and Suda T (2011) p57 kip2 and p27 kip1 cooperate to maintain hematopoietic stem cell quiescence through interactions with hsc70. Cell Stem Cell 9:247-261.

\section{Internet Resources}

European Genome-phenome Archive, https://www.ebi.ac.uk/ega/home (accessed 21 August 2014).

\section{Supplementary material}

The following online material is available for this article: Figure S1 - Kaplan-Meier curves for three-biomarker signatures.

Associate Editor: Emmanuel Dias Neto

License information: This is an open-access article distributed under the terms of the Creative Commons Attribution License (type CC-BY), which permits unrestricted use, distribution and reproduction in any medium, provided the original article is properly cited. 